\title{
Exploring Evidence Based Practice Methods for Trafficking Survivors
}

\author{
Nairruti Jani ${ }^{*}$, Jayanta Gupta ${ }^{2}$, \& Yaro Garcia ${ }^{3}$ \\ ${ }^{1 *}$ Associate Professor, Department of Social Work, Florida Gulf Coast University, United States. \\ ${ }^{2}$ Associate Professor, Department of Health Sciences, Florida Gulf Coast University, United States. \\ ${ }^{3}$ Assistant Professor of Mental Health Counseling, Florida Gulf Coast University, United States.
}

Article Details
Article Type: Research Article
Received date: $19^{\text {th }}$ May, 2021
Accepted date: $30^{\text {th }}$ July, 2021
Published date: $02^{\text {nd }}$ August, 2021
$\quad$ Corresponding Author: Nairruti Jani, Associate Professor, Department of Social Work, Florida Gulf Coast University,
United States. E-mail: njani@, fgcu.edu
Citation: Jani, N., Gupta, J., \& Garcia, Y. (2021). Exploring evidence based practice methods for trafficking survivors. JMent
Health Soc Behav 3(2):146. https://doi.org/10.33790/jmhsb1100146
Copyright: C2021, This is an open-access article distributed under the terms of the Creative Commons Attribution License
4.0, which permits unrestricted use, distribution, and reproduction in any medium, provided the original author and source are
credited.

\section{Abstract}

Human trafficking is a major crime with millions of victims globally. The issue has come to increased attention in the past twentyfive years, and much progress has been made in rescue efforts by law enforcement agencies. Unfortunately, the same pace has not been seen in understanding the public health crisis associated with this, nor has much attention been paid to the psychological consequences and treatment. Although a number of risk and protective factors for the health consequences of human trafficking victims have been identified, there is still a dearth of information in the area of intervention and treatment. In reviewing current literature, we could not find articles comparing the different components of prevailing trauma treatment strategies, and the potential usefulness of these strategies in the treatment of human trafficking victims. To this end, we surveyed mental health professionals from Florida about their experience in working with this population and treatment strategies they have found effective in working with this population. Based on prevailing research, we also tried to understand the usefulness of current treatment strategies and methods used with this population. Based on the results of our study, we conclude that mental health providers who work with human trafficking victims should become aware of treatment efficacy. Further research on the effectiveness of treatment strategies used with victims/survivors of human trafficking is needed to validate our recommendations.

\section{Background}

The nature of sex trafficking is fast, repetitive, and extended sexual exploitation by one handler (the trafficker) to many purchasers (the customers). This places its victims at some of the highest physical and mental health risks $[1,2,3]$. It is essential for treatment success that professionals expand their understanding and knowledge of what it means to survive sex trafficking. Interviewing, advocating, treating, and the overall client relationship with survivors of sex trafficking is dependent on the level of understanding the professional processes throughout the phases of helping the survivor.

Research on maltreated children has revealed that the length of the abuse, maltreatment type, severity, the timing of the abuse, and relationship with the perpetrator all play a role in the trauma [4,5]. A study by Cole et al. [6] suggested that exploitation experienced by survivors of commercial sex may have unique effects on the youth's trauma symptoms, which may require professionals to adjust and adapt their treatment approaches. Other factors that create barriers to treatment, services, and responses available to human service professionals include the lack of understanding and the complexities of sex trafficking trauma. Another study conducted with 206 survivors of sex trafficking by Zimmerman et al. [7] indicated that specialized psychological support is required because of prolonged post-traumatic stress and the time it takes the survivor to comfortably disclose their experience.

To be in a helping role, the professional must be involved in the person's personal growth and addressing the problems of a person's physical, psychological, intellectual, emotional or spiritual wellbeing [8]. The largest quantitative survey to date, conducted among 387 children and adolescent trafficking survivors, found that $56 \%$ screened positive for depression, $33 \%$ for an anxiety disorder, and $26 \%$ for PTSD [9].

There is a crucial need for information that will assist human service professionals to utilize the most knowledgeable practices. In the future, this may ensure not only the wellbeing of the survivors but also the overall success of treating and combating human trafficking $[10,11,12]$. The use of effective treatment approaches can reduce the risk of further harm, hence the importance of understanding trauma bonding for victims of sex trafficking is essential. Johnson [13]discussed the importance of aftercare service providers' understanding of the complexity, impact, and symptoms of the trauma and disclosure in sex trafficking. Results found that understanding of complex trauma and its impact will improve treatment and care for trafficked victims. Primary care providers should incorporate mental health screening into routine care, with consistent observation for distress, even after the immediate post-trafficking period [9].

Interviewing, advocating, treating, and the overall client relationship with survivors of sex trafficking is dependent on the level of understanding the professional processes throughout the phases of helping the survivor. Home and Woods [2] conducted semi-structured interviews to collect data from 11 professionals that included nurses, clinical directors, anti-trafficking task force members, social workers, and anti-trafficking program developers, working with sex trafficking survivors. The semi-structured interview was used to acquire information about the experiences of trauma, mental health consequences, and ways to effectively help sex trafficking survivors with healing and recovery [2].

In another study, memory problems were found to significantly compromise the survivor's ability to recall details of their trauma and the crimes committed against them. The study results suggested that professionals assisting survivors should be specially trained to support the survivor's process that includes memory difficulties and psychological distress [7]. A recent study by Cunningham \& Cromer 
[14] with 409 participants revealed that human trafficking myth acceptance was a significant predictor of victim blame, denying, or justifying the sale of a person, belittling the victim, excusing the perpetrator, and obscuring human trafficking. Blaming is a crucial reason as to why victims do not disclose being exploited to family, friends, and service professionals $[15,16]$. Therefore, professional treatment is essential as the survivor begins to process the sex trafficking experience.

The results from the study by Kiss et al. [9] (mentioned earlier), revealed that $55.8 \%$ of the children reported feelings of guilt or shame and about $34 \%$ were still afraid of the trafficker or his or her associates. In addition, approximately $12 \%$ of the participants reported they had attempted to harm themselves in the month prior to receiving services. Their finding was an important indicator of the need for human service professionals to provide appropriate screening, understand the survivor's process, prevent recurrence of self-harm, and help child survivors cope with a frightening future.

It has been suggested that the dearth of appropriate treatments has led to a lack of information because sex trafficking survivors are not provided with the needed processes to encourage disclosure $[7,17]$. Without awareness followed by a careful understanding of the psychological experiences of survivors, it is nearly impossible to succeed in providing appropriate treatment for survivors [18]. The difficulties while talking to professionals have been found to destabilize them further, exacerbate somatization, and prompt treatment dropout [19].

Human service professionals play a significant role in understanding the intricate and complex needs of sex trafficking survivors [20-23]. However, the literature available to date provide human service providers with little information on how to work through the disclosure process of emotionally bonded sex trafficking survivors [2,10,24,25].

Current, though limited research on trafficking victims suggests that trafficked and sexually exploited children may experience a myriad of trauma-related symptoms ranging from depression, anxiety, social isolation, and distrust to dissociation and personality splitting [26, 3]. However, data regarding clinical and mental health best practices are sparse. Zimmerman et al., [7] recommended a recovery and reflection period of a minimum of 90 days to allow the survivor to decide, consent, and provide reliable information to professionals about their experience. Trafficking victims have unique needs; however, the literature available to date has left human service professionals with limitations on how to work through the many clinical exceptional needs victims have [2].
As evident from the above studies, women who have been trafficked for the purpose of sexual exploitation are likely to have experienced multiple traumatic events and are at risk of PTSD. Little is known about the effectiveness of treatments for this group. In this pilot study, we surveyed mental health service providers in Florida about their perception of effective treatment methods compared to those commonly used in practice with victims of human trafficking.

\section{Methods}

Study subjects, instrument, and design: Due to the limited availability of participants and funds to conduct the study, a targeted purposive sampling method was used. Considering that a sample frame of mental health service providers does not exist, a voluntary recruitment email was sent out to a network of agencies in Florida and to 84 participants that attended two human trafficking conferences held at the Florida Gulf Coast University (FGCU) in 2018 (1) The Antidote Conference and (2) Human Trafficking Symposium; 38\% responded. Mental health practitioners who participated in the study included social workers, psychologists, psychiatric nurses, mental health counselors, case managers, and trauma counselors. A ten-question pilot survey that was designed primarily to explore the perception of practitioners about the effectiveness of current treatments used with victims of trafficking was administered online to consenting participants using Survey Monkey. Three percent of surveys were not included in the study because they missed more than three questions or did left the survey blank. Incomplete surveys and responses from practitioners who never served victims of human trafficking were not included in this study.

Data analysis: Descriptive statistics from the survey data were generated using Microsoft Excel.

\section{Results}

The results of this study indicated that all the victims served by mental health practitioners who participated in this study had experience in working with women victims of human trafficking. Nine percent of the participants had served both victims of labor and sex trafficking, while ninety-one percent had served victims of sex trafficking. Twenty-six percent of the participants had worked for less than one year, twenty-eight percent had worked between one to five years and forty-six percent had worked for more than 5 years as a mental health practitioner. Despite the range of experience level, most practitioners had served domestic minor victims of sextrafficking during their careers.

Of the early intervention and trust building methods, the most commonly used one was often visitation (55\%), followed by passive interviewing (37\%) and group work (8\%). Indirect exposure and ethnographic methods were not used at all. (Figure 1)

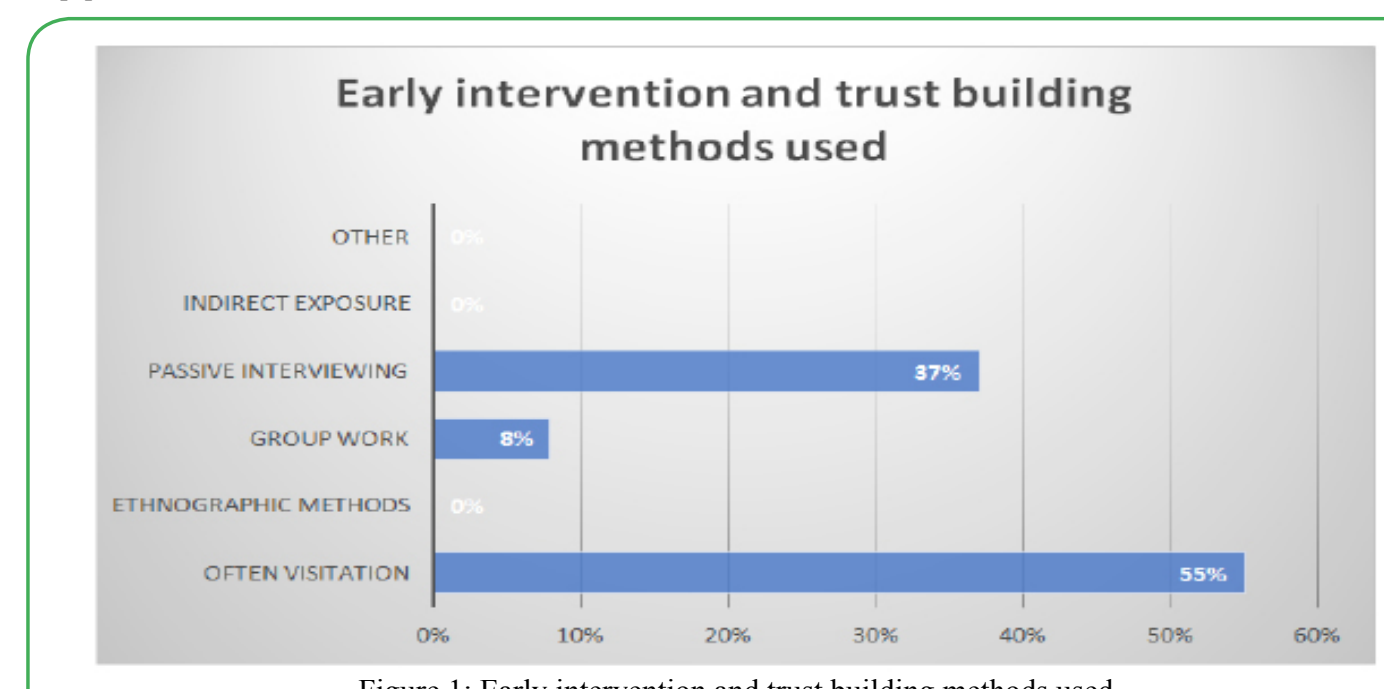

Figure 1: Early intervention and trust building methods used. 
Practitioners used multiple therapeutic methods to serve victims of human trafficking, with no particular method taking precedence. Majority (65\%) used a combination of different therapies. (Figure 2)

\section{Therapies used by practitioners to serve victims of trafficking}

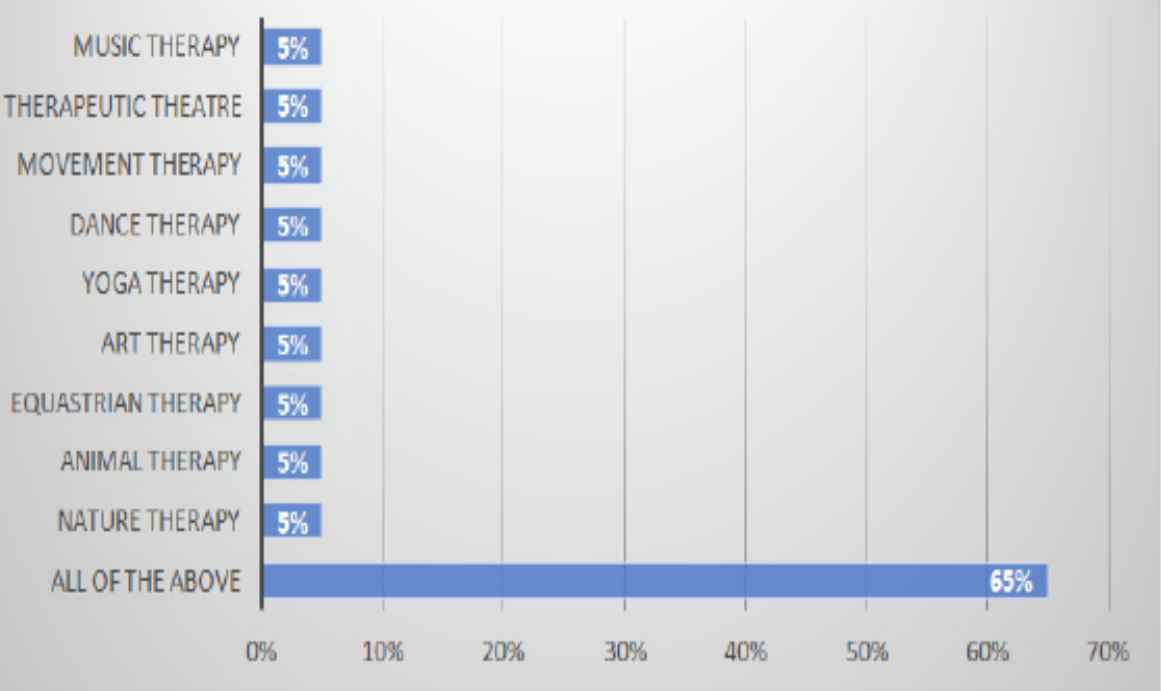

Figure 2: Therapies used by practitioners to serve victims of trafficking

No single intervention method seemed to be widely used by practitioners. While motivational interviewing was the most frequently used (28\%), other methods (acceptance and commitment, psychotherapy, narrative approach, trauma intervention, and cognitive behavioral therapy) had a consistent usage rate of only $12 \%$. Prolonged exposure and traumatic incident were not used at all.

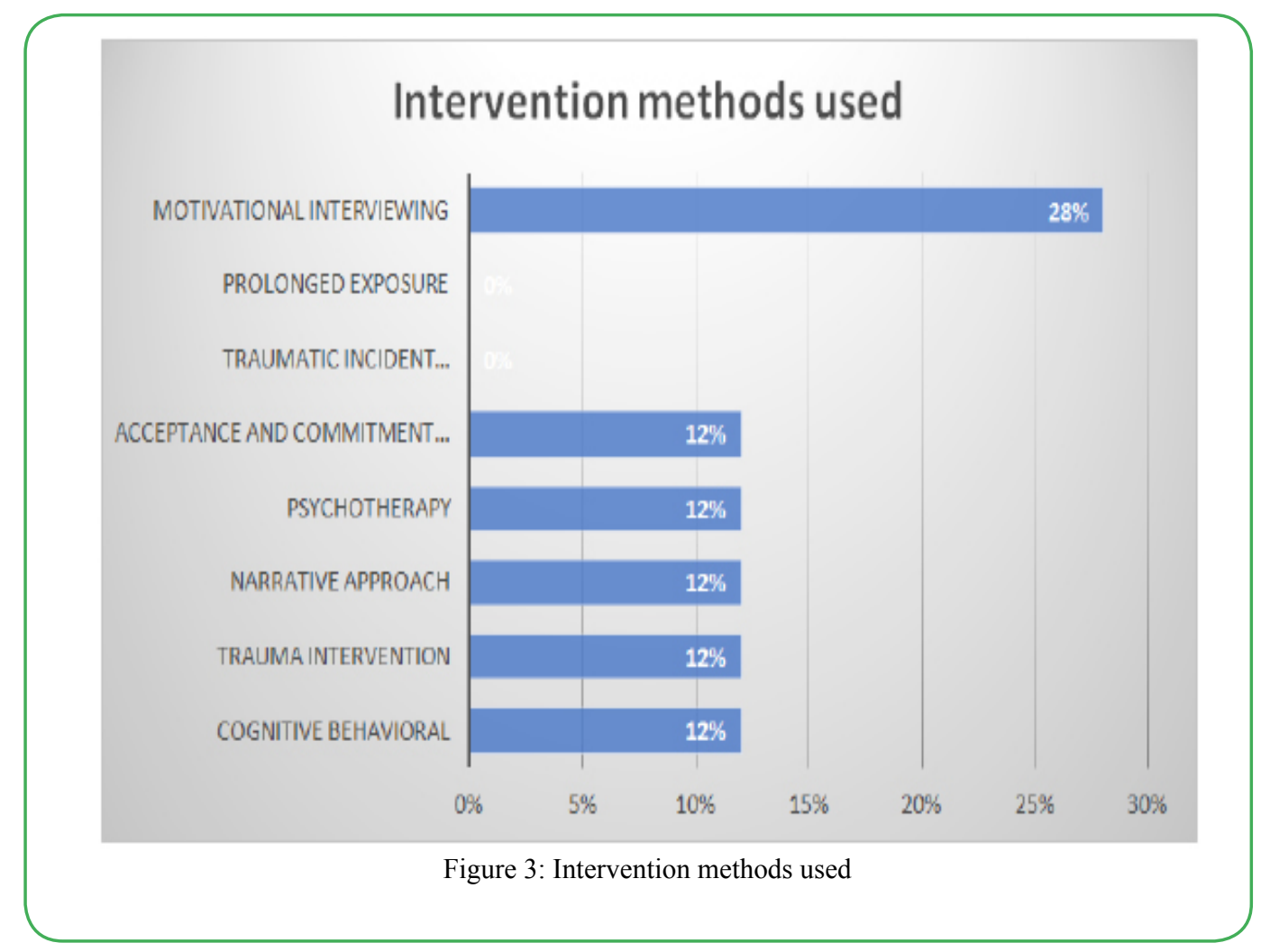




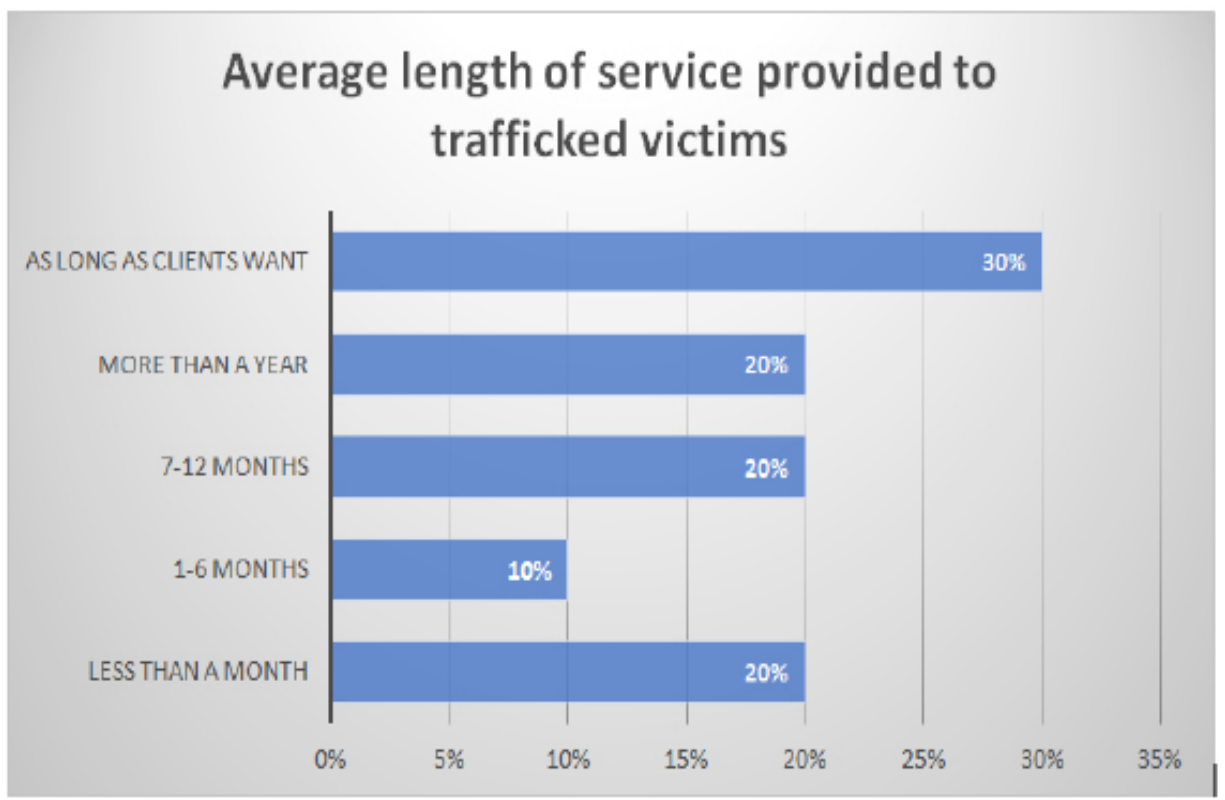

Figure 4: Average length of service provided to trafficked victims

\section{Perception about evidence-based practice methods available to serve trafficked victims}

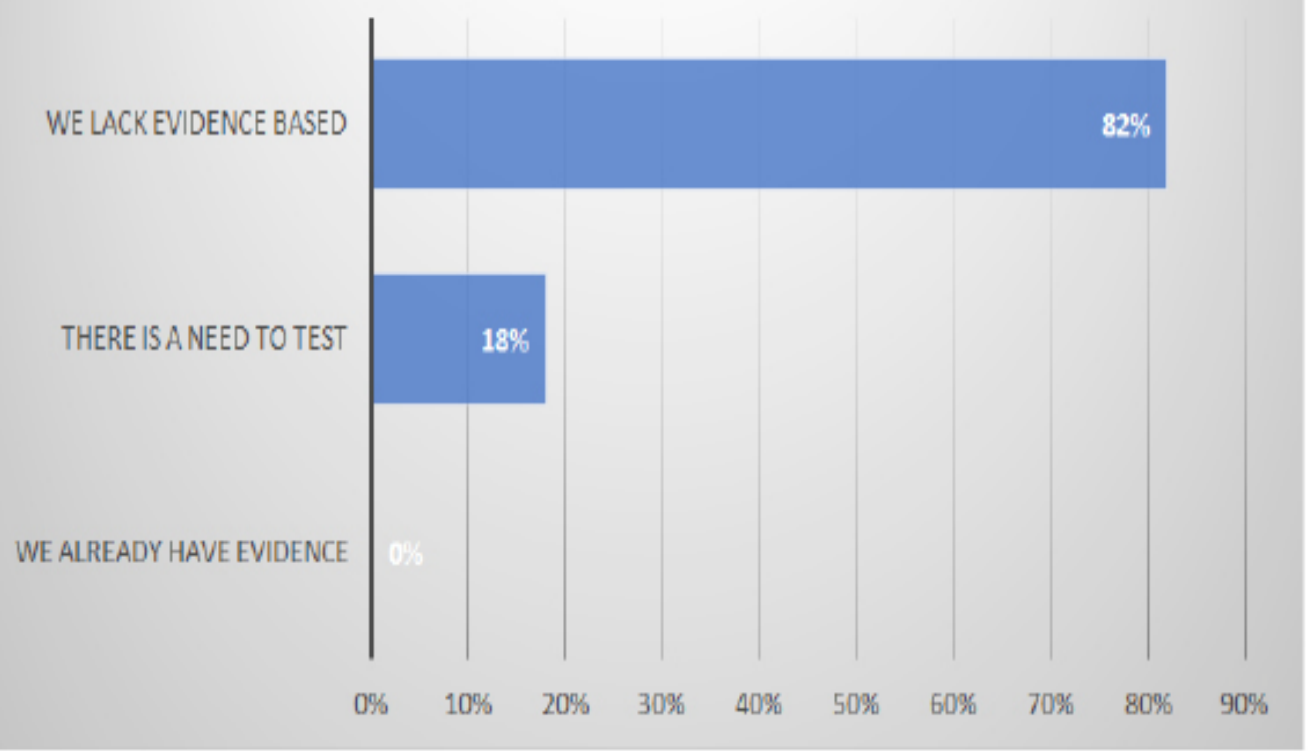

Figure 5: Perception about evidence-based practice methods available to serve trafficked victims

\section{Discussion}

Victims of human trafficking have often experienced complex trauma. Complex trauma has been linked to trauma endured during periods of extended captivity and has been directly associated with human trafficking [27]. Victims suffering from complex trauma often suffer from depression, anxiety, self-hatred, dissociation, substance abuse, despair, and somatic ailments. Individuals exposed to this type of trauma are also at heightened risk for self-destructive and risktaking behaviors as well as revictimization and tend to experience difficulty with interpersonal and intimate relationships [27].

\section{Trust Building Methods of Practice}

Literature on anti-trafficking approaches from both mental health practitioners and law enforcement suggest that victims are very fearful of outsiders, especially law enforcement officers 
"Victim fear of law enforcement is common because many foreign national and U.S. citizen victims may have had negative experiences with law enforcement and consequently are afraid to trust and cooperate with them. Moreover, traffickers often use the fear of law enforcement to control victims, setting up law enforcement as the adversary" (OVC, 2020). It is noted that due to the complexity of the trauma experienced, trafficking victims can have difficulty establishing rapport and trust with figures of authority like clinicians, and this difficulty is likely to persist beyond the period of captivity. Interacting with health care professionals can be anxiety provoking for trafficked persons whose exploitation is frequently intertwined with histories of abuse, neglect, rejection, and betrayal by family, friends, and intimate partners; and people in child welfare, education, and other positions of trust. Also, because of the threat of retaliation by a trafficker against a trafficked person and his or her loved ones, the mere possibility of being identified as trafficked could be a source of fear and internal conflict even if the trafficked person wants to be recognized as a victim and assisted [28]. Victim centered intervention is considered an appropriate approach to work with victims of human trafficking. Unfortunately, human trafficking victims are interviewed by multiple practitioners after they are rescued. Starting from law enforcement officers, emergency staff, nurses, mental health professionals, and media personnel in some cases. Majority victims of human trafficking have a history of child abuse. Abuse in childhood creates a vacuum and often leaves these children vulnerable to human trafficking. The breach of trust experienced from authority figures or strangers in the childhood, coupled with brain washing techniques employed by traffickers to keep these victims enslaved to create a deep-rooted fear of strangers among this population. It is difficult for human trafficking victims to trust caregivers and healthmental health practitioners based on their conditioning and trauma. Professionals who work with this population are often aware of this reality, especially mental health practitioners. However, current law enforcement and health mental health practice methods do not focus enough on trust-building methods proven effective while working with this population. From the total number of respondents who participated in this study, the majority focused on frequent visitation (55\%), followed by passive interviewing (37\%) and group work $(8 \%)$.

Due to the lack of research on trust-building methods and the efficacy of those methods, there is still some haze among practitioners about the non-intimidating methods they can use to build trust with their clients. Client retention, especially among group homes and shelters that house minor victims of human trafficking, is a serious issue. Further research is needed in identifying methods that can help retain this population in therapy.

\section{Self-directed methods of healing}

'Body keeps the score', trauma-informed practice and interventions are currently used in practice with victims of human trafficking. These methods focus on the need to realize and understand that trauma can be triggered during mental health practice with sensitive populations including the population of trafficked victims. Unfortunately, a continuous betrayal of trust or betrayal of trust in authority / older figures in the cases of child abuse and minor victims of trafficking presents practitioners with multiple diagnoses requiring a multifolded treatment approach. In this situation, communication using language becomes the most difficult aspect of therapy. Language is the vehicle therapists often use to heal. Unfortunately, with victims of human trafficking that primary channel of communication is blocked due to past experiences and multiple interview attempts after the rescue. Non-verbal approaches in therapy can be used to reduce symptoms of stress, anxiety, and depression. Mental health practitioners who participated in this study indicated that using some non-verbal relaxation approaches can improve treatment outcomes with victims of human trafficking. Sixty-five percent $(65 \%)$ of participants suggested that a combination of non-verbal methods were perceived to be effective while working with victims of human trafficking. These approaches range from use of music, theatre, movement, art and animal therapies including dance, yoga, equestrian, nature and animal therapies.

\section{Testing evidence-based practice methods for trafficked victims}

The primary objective of this study was to understand which methods are used by mental health practitioners who work with victims of human trafficking. Also, the study aimed at understanding the types of methods currently being used in practice that can be studied in the future to further test each of those methods and create evidence-based practice models for victims of human trafficking. Eighty-two percent of respondents noted that mental health practitioners lack evidencebased models to serve victims of human trafficking. Eighteen percent of respondents suggested that there is a need to test existing mental health practice methods with this population to find the impact of these methods on the population of human trafficking victims. Future studies in this direction can guide effective practice with victims of human trafficking and improving our scientific knowledge base.

Existing research suggests that trauma and abuse suffered by victims of human trafficking is similar to certain other populations like war veterans, domestic violence victims, and victims of child abuse. At the same time, this population is very unique in the gravity of trauma and multi-fold experiences of abuse.

Trauma informed care has been used to treat trauma suffered by trafficked victims for the past decade, alongside other clinical treatments. Unfortunately, the literature on the efficacy of this method and clinical therapy is not clear. More importantly, there have been no studies of the effectiveness of current therapies used to treat victims of human trafficking. The importance of effectiveness studies on therapies for the victims of human trafficking is critical, as evidenced by the results of this study as well as existing literature. Trauma informed care is an important approach to understand this population. However, it is not designed to treat specific symptoms or syndromes (Office of Mental Health and Addiction Services, 2008). These are therapies that have been extensively investigated with high-quality efficacy studies on similar populations, although, the application of these therapies on this population needs to be further researched.

In our study, we were not able to find a specific therapeutic method preferred by practitioners who have served victims of trafficking. Some reports on human trafficking state that the health needs of this population are similar to those of other marginalized groups such as migrant laborers, victims of sexual abuse or domestic violence, and victims of torture [29,30,31]. Considering this, pending sufficient evidence-based research mental health treatment of human trafficking, research conducted with similar populations can be examined to provide a foundation for the treatment of this population.

As per limited literature on this topic, cognitive-behavioral therapy that includes cognitive restructuring and exposure therapy, eye movement desensitization and reprocessing as well as stress inoculation training have been found to be effective treatments for PTSD suffered by similar populations [32, 33,34]. In present study, twelve percent participants found that CBT is useful in treating victims of human trafficking. The important aspects to further research in this field include research on trust building methods to work with this population, research on finding guided self-directed approaches and testing the efficacy of practice methods used with this population.

\section{Conclusion}

In conclusion, evidence-based research on testing currently used therapeutic techniques and methods to understand and treat PTSD 
and commonly related diagnoses for trafficking victims is necessary to improve outcomes of mental health practice with this population. Another significant finding from this research reveals that mental health practitioners recognize the issue of multiple interviewing of trafficked victims post rescue and its ability retraumatize victims. Thus, trust-building and appropriate approaches in gaining the trust of rescued victims is important prior to treatment. To this end, selfdirected approaches may have an important role to play in working with trafficked victims. Alternate forms of art and animal therapy are another valuable resource that can be useful in working with this population. Cognitive-behavioral therapy and Trauma-informed care and narrative exposure therapy are the mental health interventions currently prescribed in literature as effective in working with victims of human trafficking. However, findings from this pilot study revealed a serious need to conduct research on testing multiple interventions found effective by practitioners who have worked with the population of trafficked victims.

\section{Implications for research and practice and policy}

United States Department of Justice has taken active measures to combat the crime of human trafficking, resulting in an emerging need to increase to understand the health and mental health needs of this population. In the past decade, some intervention methods have been utilized by practitioners who work with this population. Efficacy studies of mental health treatment and interventions are needed in this field to promote evidence-based methods of practice. Practice informs research and research informs practice. Although limited by sample size and design, the results of this pilot study are useful to derive from practice wisdom the important needs in terms of research with the population of trafficked victims. Also, given the paucity of existing evidence about the hurdles and benefits in treating victims of trafficking, this survey establishes a need to test the reliability of treatments currently administered to trafficked victims. Women who have been trafficked for the purpose of sexual exploitation are likely to have experienced multiple traumatic events and are at risk of PTSD. Little is known about the effectiveness of treatments for this group. The primary research implication of this study is the identification of a need to further research on evidence-based practice while dealing with trauma and comorbid disorders typically suffered by victims of trafficking. The second most important implication for research and practice in this field is the trust-building early intervention techniques used by participants that can guide future research and practice. Policies to appropriate funding in conducting evidencebased research to aid practice with victims of human trafficking could result in improving mental health practice and reducing reentry of trafficked victims in the world of crime and slavery.

\section{Limitations}

The research study involved piloting a survey that examined potential research on the effectiveness of mental health practice methods currently used to serve victims of human trafficking. In terms of research, the study is limited to non-experimental research design limited to non-probability sampling and limited sample size. Also, considering the risks associated with participants who work with this sensitive population demographic information like gender identity, race/ethnicity, age were not collected in this survey. An expansion of this study is important with additional funding and a larger sample frame. Another limitation within this research study would be the lack of demographics collected on the participants of the study. It is important to test the results of this study by replicating the survey on a national scale with larger sample size and include more of the information regarding the participants. The benefits of this study outweigh the limitations, as the study creates an opportunity to conduct further research and develop evidence-based practice methods for victims of human trafficking.
Competing interests: The authors declare that they have no competing interests.

\section{References}

1. Demleitner, N. V. (2001). The law at a crossroads: The construction of migrant women trafficked into prostitution. In D. Kyle \& R. Koslowski (Eds.), Global human smuggling: Comparative perspectives (pp. 257-293). Baltimore: Johns Hopkins University Press.

2. Hom, K. A., \& Woods, S. J. (2013). Trauma and its aftermath for commercially sexually exploited women as told by frontline service providers. Issues in Mental Health Nursing, 34(2), 75-81. Retrieved from http://doi.org/10.3109/01612840.2012.7 23300

3. Greenbaum, J., Crawford-Jakubiak, J. E., \& Committee on Child Abuse and Neglect. (2015). Child sex trafficking and commercial sexual exploitation: health care needs of victims. Pediatrics, 135(3), 566-574.

4. Isobel, S., Goodyear, M., \& Foster, K. (2019). Psychological Trauma in the Context of Familial Relationships: A Concept Analysis. Trauma, Violence, \& Abuse, 20(4), 549-559. Retrieved from https://doi.org/10.1177/1524838017726424

5. Kelly, P., Viding, E., Puetz, V., Palmer, A., Mechelli, A., Pingault, J., . . . McCrory, E. (2015). Sex differences in socioemotional functioning, attentional bias, and gray matter volume in maltreated children: A multilevel investigation. Development and Psychopathology, 27(4pt2), 1591-1609.

6. Cole, J., Sprang, G., Lee, R., \& Cohen, J. (2016). The trauma of commercial sexual exploitation of youth: A comparison of CSE victims to sexual abuse victims in a clinical sample. Journal of interpersonal violence, 31(1), 122-146.

7. Zimmerman, C., Hossain, M., Yun, K., Roche, B., Morison, L., \& Watts, C. (2006). Stolen smiles: A summary report on the physical and psychological health consequences of women and adolescents trafficked in Europe. London: London School of Hygiene \& Tropical Medicine.

8. O'Grady, K. A., \& Richards, P. S. (2010). The role of inspiration in the helping professions. Psychology of Religion and Spirituality, 2(1), 57.

9. Kiss L, Yun K, Pocock N, Zimmerman C. Exploitation, Violence, and Suicide Risk Among Child and Adolescent Survivors of Human Trafficking in the Greater Mekong Subregion. JAMA, Published online September 01, 2015

10. Cecchet, S. J., \& Thoburn, J. (2014). The psychological experience of child and adolescent sex trafficking in the United States: Trauma and resilience in survivors. Psychological Trauma: Theory, Research, Practice, and Policy, 6(5), 482-493. Retrieved from http://dx.doi.org/10.1037/a0035763

11. Ullman, S. E., \& Peter-Hagene, L. C. (2016). Longitudinal Relationships of Social Reactions, PTSD, and Revictimization in Sexual Assault Survivors. Journal of Interpersonal Violence, 31(6), 1074-1094. Retrieved from https://doi. org/10.1177/0886260514564069

12. Williams, L. M., \& Frederick, M. E. (2009). Pathways into and out of commercial sexual victimization of children: Understanding and responding to sexually exploited teens. Lowell, MA: University of Massachusetts Lowell.

13. Johnson, B. C. (2012). Aftercare for Survivors of Human Trafficking. Social Work \& Christianity,39(4),370-389. Retrievedfrom http://search.ebscohost.com/login.aspx?direct=t rue $\& d b=a 9 h \& A N=83406592 \&$ site $=$ eds-live 
14. Cunningham, K. C., \& Cromer, L. D. (2016). Attitudes About Human Trafficking: Individual Differences Related to Belief and Victim Blame. Journal of Interpersonal Violence, 31(2), 228 244. Retrieved from https://doi.org/10.1177/0886260514555369

15. Hébert, M., Van Camp, T., Lavoie, F., Blais, M., \& Guerrier, M. (2014). Understanding the hesitancy to disclose teen dating violence: Correlates of self-efficacy to deal with teen dating violence. Temida : casopis o viktimizaciji, ljudskim pravima $\mathrm{i}$ rodu, 17(4), 43-64. doi:10.2298/TEM1404043H

16. Franklin, C. A., \& Menaker, T. A. (2015). The Impact of Observer Characteristics on Blame Assessments of Prostituted Female Youth. Feminist Criminology, 10(2), 140-164. Retrieved from https://doi.org/10.1177/1557085114535234

17. Nichols, A. J., \& Heil, E. C. (2015). Challenges to Identifying and Prosecuting Sex Trafficking Cases in the Midwest United States. Feminist Criminology, 10(1), 7-35. Retrieved from https://doi.org/10.1177/1557085113519490

18. Wolfe, A. K. (2015). Human Trafficking \& Commercial Sex Exploitation: Treatment Recommendations for an Invisible Population.

19. Judge, A. M., Murphy, J. A., Hidalgo, J., \& MaciasKonstantopoulos, W. (2018). Engaging survivors of human trafficking: complex health care needs and scarce resources. Annals of internal medicine, 168(9), 658-663.

20. Hammond, G. C., \& McGlone, M. (2014). Entry, progression, exit, and service provision for survivors of sex trafficking: Implications for effective interventions. Global Social Welfare, 1(4), 157-168.

21. Hodge, D. R. (2014). Assisting victims of human trafficking: Strategies to facilitate identification, exit from trafficking, and the restoration of wellness. Social Work, 59(2), 111-118.

22. Hofmann, T. B., Garcia, Y. (2015). Partnership, The Fourth P, Enhances HT Service Efforts in Prevention, Protection and Prosecution Arenas, Slavery Today Journal, 2(2), 1-15.

23. Hornor, G. (2015). Domestic minor sex trafficking: What the PNP needs to know. Journal of Pediatric Health Care, 29(1), 88-94.

24. Cole, J., \& Sprang, G. (2015). Sex trafficking of minors in metropolitan, micropolitan, and rural communities. Child abuse \& neglect, 40, 113-123.
25. Reid, J. A., Huard, J., \& Haskell, R. A. (2015). Family-facilitated juvenile sex trafficking. Journal of Crime and Justice, 38(3), 361-376.

26. Domoney, J., Howard, L. M., Abas, M., Broadbent, M., \& Oram, S. (2015). Mental health service responses to human trafficking: a qualitative study of professionals' experiences of providing care. BMC psychiatry, 15(1), 289.

27. Courtois, C. A. (2008). Complex trauma, complex reactions: Assessment and treatment. Psychological Trauma: Theory, Research, Practice, and Policy, S(1), 86-100. https://doi. org/10.1037/1942-9681.S.1.86

28. Macias-Konstantopoulos WL, Munroe D, Purcell G, Tester $\mathrm{K}$, Burke TF, Ahn R. The commercial sexual exploitation and sex trafficking of minors in the Boston metropolitan area: experiences and challenges faced by front-line providers and other stakeholders. J Appl Res Child. 2015;6(1):4. http:// digitalcommons.library.tmc.edu/cgi/viewcontent.cgi?article $=12$ $42 \&$ context $=$ childrenatrisk. Accessed November 21, 2016.

29. Clawson, H. J., Salomon, A., \& Grace, L. G. (2008). Treating the hidden wounds: Trauma treatment and mental health recovery for victims of human trafficking. US Department of Health and Human Services, Office of the Assistant Secretary for Planning and Evaluation.

30. International Organization for Migration. (2006). Breaking the cycle of vulnerability: Responding to the health needs of trafficked women in east and southern Africa. Pretoria, South Africa.

31. David J. Zimmerman, (2003). "Peer Effects in Academic Outcomes: Evidence from a Natural Experiment," The Review of Economics and Statistics, MIT Press, vol. 85(1)

32. Bradley, R., Greene, J., Russ,E., Dutra, L., Westen, D., (2005). A multidimensional meta-analysis of psychotherapy for PTSD. Am J Psychiatry, 162(2):214-27. doi: 10.1176/appi.ajp.162.2.214.

33. Rauch, S.A.M., Cahill, S.P., (2003). Treatment and Prevention of Posttraumatic Stress Disorder. Primary Psychiatry. 2003; 10(8):60-65

34. Ursano, R.J., Bell, C., Eth, E., Friedman, M., (2004). Practice guideline for the treatment of patients with acute stress disorder and posttraumatic stress disorder. Am J Psychiatry, 161(11 Suppl):3-31. 